\title{
ESPORTE COMO PRODUTO DA SOCIEDADE DO ESPETÁCULO: A EXPANSÃO DO CAPITAL E IMPLICAÇÕES PARA A EDUCAÇÃO FÍSICA
}

\author{
Gustavo Amancio Bonetti Meneghel ${ }^{1}$ \\ Bruno Beloli Milioli ${ }^{2}$ \\ Gabriel Pessi Da Rolt ${ }^{3}$
}

\begin{abstract}
Resumo: O debate sobre espetáculo no qual Guy Deboard (1997) inicia no fim dos anos 50 e dedica sua afirmação até sua morte em 1994 é atualíssimo. O fato de vivermos em uma sociedade fundada nos modos de produção capitalista, necessariamente nos emerge ao espetáculo. Todas as formas de manifestação humana ficam refém do capital. Expressões como arte, mídia, política, esporte... tem como base as relações de valorização do valor, no qual só "vive" quem produz e estabelece relação de troca (DEBOARD, 1997). Nossa proposta é analisar o esporte como produto do espetáculo, proporcionado pelo capital, no qual influencia diretamente a forma e o conteúdo dessa pratica da Cultura Corporal. Para isso, adotamos como procedimentos de pesquisa o estudo bibliográfico, no qual iremos relacionar o esporte fundado no espetáculo e suas consequências na sociedade capitalista. A expansão do esporte espetáculo no mundo é dada por decisões políticas que levam os megaeventos a locais onde pode ser melhor explorada essa relação de consumo. Um exemplo claro é a copa do mundo de futebol de 2010, realizada na África do Sul, abrindo fronteiras para a comercialização do futebol no continente africano, atingindo mais pessoas e influenciando o continente africano a consumir o futebol. Buscamos em Deboard, uma leitura critica da realidade para compreendermos o fenômeno esportivo como metabolismo ativo da sociedade do espetáculo. Palavras-chave: Espetáculo, Esporte, Capitalismo.
\end{abstract}

\section{SPORT AS A PRODUCT OF THE SOCIETY OF SPECTACLE: THE EXPANSION OF CAPITAL AND IMPLICATIONS FOR PHYSICAL EDUCATION}

Astract: The debate on the show in which Guy Deboard (1997) begins in the late 1950s and dedicates his statement to his death in 1994 is most recent. The fact that we live in a society based on the capitalist modes of production necessarily gives rise to the spectacle. All forms of human manifestation are held hostage by capital. Expressions such as art, media, politics, sport ... are based on valuation relations of value, in which only "lives" who produces and establishes a relation of exchange (DEBOARD, 1997). Our proposal is to analyze sport as a product of the spectacle, provided by capital, in which it directly influences the form and content of this practice of Body Culture. For this, we adopted as research procedures the bibliographic study, in which we will relate the sport based on the spectacle and its consequences in capitalist society. The expansion of the sport spectacle in the world is given by political decisions that take the mega-events to places where this relation of consumption can be better explored. A clear example is the 2010 FIFA World Cup, held in South

\footnotetext{
${ }^{1}$ Mestrando em Educação pela Universidade do Extremo Sul Catarinense - UNESC, Santa Catarina, Brasil

${ }^{2}$ Mestrando em Educação pela Universidade Federal de Santa Catarina - UFSC, Santa Catarina, Brasil

${ }^{3}$ Granduando em Educação Física pela Universidade do Extremo Sul Catarinense - UNESC, Santa Catarina, Brasil
} 


\section{Universidade do Extremo Sul Catarinense \\ Revista Ibero-Americana de Humanidades, Ciências e \\ Educação \\ UnesC Produção e democratização do conhecimento na lbero-América}

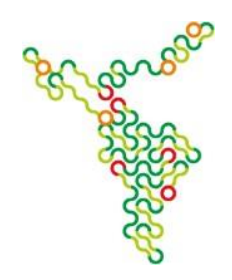

Africa, opening borders for the commercialization of football on the African continent, reaching more people and influencing the African continent to consume football. We look for in Deboard, a critical reading of reality to understand the sporting phenomenon as active metabolism of the society of the spectacle.

Keywords: Spectacle, Sport, Capitalism.

\section{INTRODUÇÃO}

O debate sobre espetáculo no qual Guy Deboard (1997) inicia no fim dos anos 50 e dedica sua afirmação até sua morte em 1994 é atualíssimo. O fato de vivermos em uma sociedade fundada nos modos de produção capitalista, necessariamente nos emerge ao espetáculo. Todas as formas de manifestação humana ficam refém do capital. Expressões como arte, mídia, política, esporte... tem como base as relações de valorização do valor, no qual o "viver" é direcionado pela classe social que as pessoas ocupam (DEBOARD, 1997)

Nossa proposta é guiada pela seguinte problemática: Qual a relação do esporte com espetáculo, proporcionado pelo capital, e qual influência dessa forma denominada esporte, nas práticas da Cultura Corporal. Nosso objetivo é analisar a relação do esporte com espetáculo, proporcionado pelo capital, e qual influência dessa forma denominada esporte, nas práticas da Cultura Corporal. Para isso, adotamos como procedimentos de pesquisa o estudo bibliográfico, no qual iremos relacionar o esporte fundado no espetáculo e suas consequências na sociedade capitalista.

No primeiro capitulo abordaremos o conceito de espetáculo em Guy Deboard e seus elementos principais, no qual as relações de produção atuais giram em volta do consumo estabelecido pelo valor de troca das mercadorias, guiando a vida coletiva a contemplação das imagens forjadas socialmente.

No segundo capítulo, trataremos de analisar o esporte nascente desse modo de produção e como ele no alto rendimento se torna veículo de consumo, como de camisas, tênis, chuteiras, ingressos, paginas na internet e etc. $\mathrm{O}$ esporte, como pratica da Cultura Corporal nasce na sociedade capitalista para atender a demanda de mercadoria na esfera que anteriormente se manifestava no jogo, na luta, no atletismo e na ginástica e como a Educação Física está lidando com a expansão do esporte, principalmente no âmbito escolar. 


\section{Universidade do Extremo Sul Catarinense \\ Revista lbero-Americana de Humanidades, Ciências e \\ Educação \\ Unesc Produção e democratização do conhecimento na lbero-Améríca}

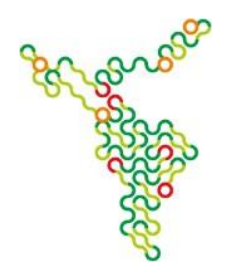

\section{O CONCEITO DE ESPETÁCULO EM GUY DEBOARD}

Como afirmamos anteriormente, desde a revolução industrial e o estabelecimento dos modos de produção capitalista, a sociedade é movida pela relação troca de mercadorias, no qual Guy Deboard (1997, p.13) em sua grande obra, A Sociedade do Espetáculo afirma que "Toda a vida das sociedades nas quais reinam as condições modernas de produção se anuncia como uma imensa acumulação de espetáculos. (grifo do autor) Tudo que era diretamente vivo se esvai na fumaça da representação". O ser humano individualizado na esfera consumo é movido por representações, no qual motivam os mesmos a vender sua força de trabalho para depois, trocar sua própria produção que não é dele, mas sim do dono dos meios de produção pelo valor recebido na relação de trabalho. Em sua $4^{\circ}$ tese, Deboard (1997, p.14) define que "O espetáculo não é um conjunto de imagens, mas uma relação social entre pessoas, mediada por imagens". O poder do espetáculo atinge todas as esferas de vida humana, subordinando-nos a uma vida mediada por imagens.

Podemos chamar o efeito do espetáculo como uma "idolatria" ao consumo. O indivíduo é direcionado ao consumo estranhado desde criança mesmo que ainda dependa dos pais ou responsáveis para tal efetivação por meio das relações midiáticas, nas quais o poder da mesma é tão grandioso e influenciador que direciona a compra de tal produto de tal marca por um valor maior do que um produto de uma marca menos conhecida, somente pela existência de um nome famoso na estampa ou na etiqueta da roupa (JAPPE, 1999).

A alienação do espectador em favor do objeto contemplado (o que resulta da sua própria atividade inconsciente) se expressa assim: quanto mais ele contempla, menos vive; quanto aceita reconhecer-se nas imagens dominantes da necessidade, menos compreende sua própria existência e seu próprio desejo. Em relação ao homem que age, a exterioridade do espetáculo aparece no fato de seus próprios gestos já não serem seus, mas de um outro que os representa por ele. É por isso que o espectador não se sente em casa em lugar nenhum, pois o espetáculo está em toda parte. (DEBOARD, 1997, p.24)

No primeiro estágio de evolução histórica, a relação de alienação dava-se ao "ser" em "ter". Nesse estágio o "ter" se transforma no "parecer". Isso por que o espetáculo empobrece a vida cotidiana e separa o ser de si mesmo, estabelecendo outra "dimensão", a do consumo. A imagem na sociedade do espetáculo do poder a uma certa "hipnose" humana de contemplação da mercadoria, direcionando o motivo de sua atividade para o consumo exacerbado, fortalecendo cada vez mais a lógica do capital.

Revista Ibero-Americana de Humanidades, Ciências e Educação. Criciúma, v.6.n.1, 2020. 


\section{Universidade do Extremo Sul Catarinense \\ Revista lbero-Americana de Humanidades, Ciências e \\ Educação \\ Unesc Produção e democratização do conhecimento na lbero-América}

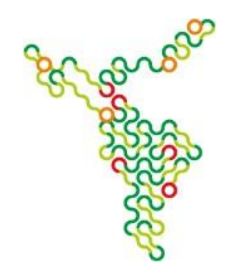

Para o estabelecimento e a manutenção do espetáculo, existem dois fundamentos essenciais: “ $<<$ A renovação tecnológica incessante $>>$ e $<<$ a fusão estatal $>>$; e na sua fase mais recente três grandes consequências: O segredo generalizado; o falso sem replica; um presente perpétuo〉> (JAPPE, 1999, p. 19).

Podemos ver em nossa sociedade a desigualdade social como marca registrada de um sistema que não beneficiou a todos, pelo contrário, garantiu aos que detém os meios de produção a dominação dos meios de vida e para isso gerou pobreza em todo o mundo. Deboard (1997) atribui esse fracasso a filosofia ocidental de vida, no qual se esvazia as relações de vida e de valor de uso da produção humana, para o engrandecimento do valor de troca, gerando lucro e mais-valia a alguns e exploração e injustiça a outros.

Uma categoria explorada pela teoria marxiana citada anteriormente, vale nossa atenção, mesmo que por hora seja com um poder de síntese. O valor de uso e de troca. Deboard (1997, p.33) se refere as categorias como

(...) o uso sobre sua forma mais pobre (comer, morar) já não existe a não ser aprisionado na riqueza ilusória da sobrevivência ampliada, que é a base real da aceitação da ilusão geral no consumo das mercadorias modernas. O consumidor real, torna-se consumidor de ilusões. A mercadoria é essa ilusão efetivamente real, e o espetáculo é a sua manifestação geral

O valor de uso que nas primeiras civilizações (chamadas de comunismo primitivo) reinava e a organização social era onde todos tinham uma função (caçar, cuidar da "casa" e da família, fogo e etc.), porém todos partilhavam do alimento, da bebida e de todas as conquistas materiais. Desde as sociedades escravocratas e feudal, mas principalmente na sociedade capitalista as categorias se invertam. Na produção, o valor de uso é encoberto pelo valor de troca, no qual a finalidade não é o uso em si, mas a venda do produto.

Mas qual é o poder do estado nessa conjuntura espetacular? Deboard (1997) apresenta no primeiro momento, dois tipos de espetáculo estruturantes ao estado. O primeiro chamado difuso, no qual a sociedade é organizada num prisma de democracia, no qual a produção da mercadoria da ao consumidor a impressão que ele tem possibilidade de escolha. O segundo, chamado de concentrado. Atribuído aos poderes totalitários, nos quais orientam e estabelecem as relações de produção, consumo e gerando assim, um capitalismo burocrático. Anos após a publicação de seu livro, A sociedade do espetáculo, Deboard, escreve em uma nova edição os "comentários sobre a sociedade

Revista Ibero-Americana de Humanidades, Ciências e Educação. Criciúma, v.6.n.1, 2020. 


\section{Universidade do Extremo Sul Catarinense \\ Revista lbero-Americana de Humanidades, Ciências e \\ Educação \\ Unesc Produção e democratização do conhecimento na lbero-América}

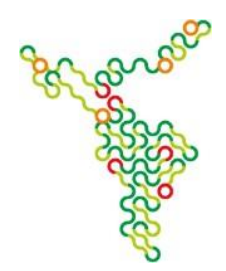

do espetáculo" (1988), no qual estabelece um novo tipo de organização do estado perante ao sistema, o integrado. Influenciado pelo poder midiático, no qual tomou proporções consideráveis, é constituído pela união dos dois primeiros e tenta imprimir-se mundialmente, devido a força que apresenta na atual sociedade.

Podemos minimamente compreender o pensamento de Deboard, em uma breve explanação sobre o conceito de espetáculo. Percebemos que a sociedade é direcionada ao consumo da produção humana e o esporte como produto histórico humano não é diferente. $\mathrm{Na}$ próxima sessão explicitaremos a ocupação do esporte na sociedade do espetáculo.

\section{O ESPORTE COMO PRODUTO DA SOCIEDADE DO ESPETÁCULO}

As praticas corporais desenvolvidas, histórico e socialmente serão chamadas de manifestações da cultura corporal (COLETIVO DE AUTORES, 1992). Tal nomenclatura carrega consigo um significado, no qual é pela atividade humana que o homem produz e reproduz ações corporais, manifestadas no jogo, dança, luta, ginástica e esporte.

Poderíamos estar nos perguntando, e o esporte, onde entra nessa produção histórica e social? Pois bem, o esporte é produto do desenvolvimento exacerbado do capital, no qual transformou as manifestações da cultura corporal em produto de espetacularização. Essa espetacularização transforma as manifestações da cultura corporal em mercadoria, no qual a produção de recordes, momentos marcantes, jogadas especiais se transformam não somente em produção da ação corporal, mas em estabelecimento de valor de troca, e consequentemente o lucro. Segundo Colombo (2015, p.1) "O esporte é atualmente um dos fenômenos sociais mais presentes na vida dos indivíduos. Tornase praticamente impossível negar sua manifestação no cotidiano destes.” Pela influencia esportiva no cotidiano das pessoas, o consumo do esporte, seja com a ascensão de mercadorias como, camisas, calças, tênis, chuteiras e etc. pela participação do torcedor, seja pela mídia (TV, rádio, internet) ou em loco, ou até pelo consumo de produtos que patrocinam o espetáculo, o esporte se torna mercadoria.

A posição do esporte na sociedade contemporânea manifesta-se em dois modos:

Em primeiro lugar, o Esporte - como forma particular de organização das práticas corporais na sociedade capitalista - permitiu o máximo de desenvolvimento dos conteúdos (ou dos objetos, propriamente ditos) das atividades da cultura corporal. Mais importante, foi através do Esporte que esses objetos puderam surgir e se desenvolver como relações gerais e 


\section{Universidade do Extremo Sul Catarinense \\ Revista lbero-Americana de Humanidades, Ciências e \\ Educação \\ unesc \\ Produção e democratização do conhecimento na lbero-América}

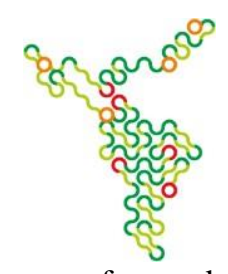

essenciais da pratica humana. Em segundo lugar, o Esporte é, igualmente uma forma de atividade na qual as relações próprias e particulares do modo de produção capitalista se objetivam (NASCIMENTO, 2014, p.74)

O esporte nasce como produto da ação corporal humana direcionada a um determinado fim, atendendo uma necessidade dos modos de produção capitalistas. Assim, esvaziando a pratica corporal e fixando relações de ganhar a qualquer custo, utilização de medicamentos, chás, drogas para melhorar a condição de performance, generalizando conflitos entre espectadores por influência da competição exacerbada que se encontra na essência do esporte.

Esse processo de espetacularização do esporte levou a criação de eventos e megaeventos em que

o momento em que a mercadoria ocupou totalmente a vida social. Os megaeventos esportivos, através da mercadoria esporte, tornam os consumidores reais em consumidores de ilusões, melhor dizendo, a mercadoria é uma ilusão efetivamente real, e o espetáculo é sua manifestação geral (PIRES; SILVA, 2009, p, 12 - 13)

Os megaeventos traduzem a influencia do capital nas práticas esportivas. Utilizando como exemplo a copa do mundo de futebol e as Olímpiadas de verão, tem em sua estrutura, uma organização de patrocinadores, com empresas de marketing, restaurantes de fastfoot, empresas de construção civil, de materiais esportivos que subsidiam o acontecimento do megaevento. Nesse circulo vicioso, o expectador consome o megaevento, de diversas formas (que já foram citadas nesse trabalho) e garantem assim, o retorno financeiro e o lucro dos patrocinadores. Para existir esse circulo vicioso e dialético de investimento/consumo e consumo/investimento precisa apresentar um ótimo produto nas competições esportivas. Esses produtos são as performances dos atletas que, pelo desenvolvimento tecnológico, da fisiologia, dos estudos sobre rendimento, cada vez mais buscam quebrar os recordes estabelecidos historicamente. Assim a atração do consumidor está garantida e o lucro do investidor também e o esportista tem sua força de trabalho vendida por um valor muito menor do que a espetacularização proporcionou para os investidores do megaevento.

Como a maioria dos trabalhadores, o esportista também se vê levado a vender sua força-detrabalho, como única possibilidade de produzir sua subsistência atuando no trabalho que sabe fazer, envolvido com o esporte. Vende para o capitalista sua força-de-trabalho nessa área, que sob condições especiais, pode apresentar um desempenho necessário para o processo produtivo. A força-de-trabalho do esportista se apresenta de diversas formas, a partir da qualificação que possua. Diferentemente do que se tinha há algum tempo atrás, quando era limitada à figura do atleta e do treinador, hoje se encontram os mais variados profissionais, como o massagista, o preparador físico, o psicólogo, o médico e o administrador. Há também outros profissionais mais distantes do fenômeno, mas não menos numerosos e que fazem dele (o esporte) a fonte de seu trabalho, como: o sociólogo, o comentarista, o empresário, o 


\section{Universidade do Extremo Sul Catarinense \\ Revista Ibero-Americana de Humanidades, Ciências e \\ Educação \\ unesc

pesquisador e o árbitro, entre outros. (SILVA, 1991, p. 52, grifo do autor)

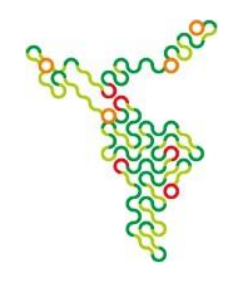

É necessário investirmos um pouco de tempo e esforço para compreendermos o metabolismo do esporte como produto do capital, na figura do atleta de alto rendimento. Ele um elemento chave para o espetáculo, sem ele não existe espetáculo e consequentemente o capital não produziria riqueza por meio do esporte. É possível notar atletas de alto rendimento participando de comerciais de produtos, ou tendo sua imagem colocada como o centro das atenções dentro do próprio clube a que pertence. $\mathrm{O}$ esporte extrapola qualquer relação de simplesmente ações corporais para determinado fim. Ele utiliza-se disso para sua expansão e concentra-se sempre onde pode ser estabelecido a relação de troca, o consumo.

A expansão do esporte espetáculo no mundo é dada por decisões políticas que levam os megaeventos a locais onde pode ser melhor explorada essa relação de consumo. Um exemplo claro é a copa do mundo de futebol de 2010, realizada na África do Sul, abrindo fronteiras para a comercialização do futebol no continente africano, atingindo mais pessoas e influenciando o continente africano a consumir o futebol. Outro exemplo é

Este movimento de absorção do esporte pelo capital ecoa na importante competição
estadunidense: NationalBasketballAssociation (NBA). No ano de 2015 a NBA anunciou
recorde de atletas estrangeiros. Também há negociação da NBA com outras ligas de
basquetebol por todo o mundo, inclusive no Brasil, para difundir o esporte e obviamente,
lucrar. Mais adeptos, mais consumos. Maior visibilidade do esporte em todo o mundo, maior
possibilidade de vendas de camisas e tênis dos grandes ídolos do esporte. (COLOMBO, 2015,
p.7)

A influencia politica de escolhas dentro do esporte, reforça e prioriza a expansão de sua espetacularização no cenário mundial, decidindo a realização de eventos em locais determinados ou até mesmo mudanças de regras para se enquadrar a TV.

Permitimo-nos a partir desse debate, voltar as primeiras considerações deste, no qual apresentamos que o esporte é a forma principal e mais evoluída na sociedade capitalista das manifestações da cultura corporal, gerada pela produção humana. O Estatuo da Criança e Adolescente (1990), afirma que toda criança tem direito e possibilidade da pratica esportiva, entretanto, todas as crianças realmente têm direito e a possibilidade de praticar Futebol, Tênis, Natação, Vôlei, Basquete, Xadrez e etc.? É evidente que não.

Em primeiro lugar, convivemos com a impossibilidade objetiva de apropriação dessas máximas potencialidade humanizadoras, presentes nas práticas corporais, para todos os indivíduos. As diversas manifestações das atividades da cultura corporal [...] fazem parte do patrimônio ou dos "bens culturais" da humanidade, de modo que deveriam ser atividades a 


\section{Universidade do Extremo Sul Catarinense \\ Revista lbero-Americana de Humanidades, Ciências e \\ Educação \\ unesc \\ Produção e democratização do conhecimento na llbero-América}

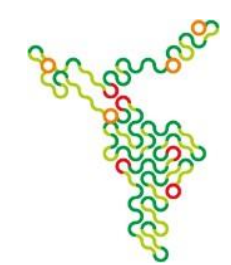

serem fruídas, apreciadas, praticadas e apropriadas pelos indivíduos pelo simples fato de materializarem em si determinadas capacidades humano-genéricas. São atividades que fazem parte (devem fazer parte) da constituição do humano em nós. Mas, como todos os bens culturais produzidos e existentes em nossa sociedade, as possibilidades objetivas para que cada indivíduo se aproprie delas não está dada. Faltam condições materiais e não materiais para que essas atividades possam de fato ser apropriadas por todos.(NASCIMENTO, 2014, p.76)

O acesso das crianças ao esporte é estritamente vinculado a escola, fundações (clubes, departamentos) esportivas e a raros casos a possibilidades na comunidade de pratica-lo. $\mathrm{O}$ esporte na escola pode ser considerado o mais democrático (ou deveria ser), no qual todos estão no processo de aprendizagem e não tem como finalidade conseguir bons resultados e performance, assim todos podem participar. Entretanto a escola não pode oferecer a apropriação de todos os esportes (ou pelo menos os mais conhecidos no cotidiano social), por falta de materiais, de conhecimento do professor e etc. assim preconizando o acesso dos estudantes aos diversos esportes. No caso do esporte em fundações esportivas, clubes e departamentos, geralmente o acesso ao esporte alguns esportes são subsidiados pelo poder público, em outros casos somente quem tem condições financeira para pagar tem acesso ao esporte. O grande problema das fundações esportivas é que elas prezam pelo desempenho qualificado do atleta na modalidade e acaba excluindo muitas pessoas que querem participar da pratica esportivas, mas "não tem" o rendimento esperado pelos técnicos. Por último, o esporte na comunidade. Na realidade brasileira, o esporte comunitário se resume a quadras de futsal e campos de futebol. Dificilmente a comunidade tem acesso a quadras de tênis, piscina para natação ou pistas de atletismo.

O que está escrito no ECA parece que não acontece na pratica. E por que não acontece? Como enfatizamos até o momento, o esporte é produto do capital que tem como premissa a venda e o consumo, tornando essa produção humana em mercadoria. Assim, o investimento no esporte fica a mercê do esporte de alto rendimento, enfraquecendo o esporte escolar e o lazer. Quem pode fazer parte do esporte de alto rendimento são aqueles que tem aptidão para a pratica, que tem performances muito acima do que é considerado socialmente "normal".

A Educação Física, como "responsável” pelos conhecimentos produzidos pelas manifestações da cultura corporal, durante seu percurso histórico vem discutindo essa temática com posicionamentos diferentes embasados em métodos filosóficos e a conjuntura social. Por exemplo, entre as décadas de 60 e 80, nos anos de ditadura militar, o esporte foi tratado como meio de atração social, buscando desviar os acontecimentos no país e direcionando os olhares ao esporte, com a 


\section{Universidade do Extremo Sul Catarinense \\ Revista lbero-Americana de Humanidades, Ciências e \\ Educação \\ unesc \\ Produção e democratização do conhecimento na Ibero-América}

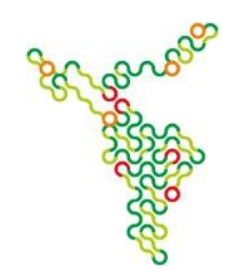

seleção de futebol campeã da copa do mundo de 1970, João do Pulo, Emerson Fittipaldi e entre outras conquistas supervalorizadas pela ditadura. A Educação Física tinha como objetivo a formação de atletas, somente os melhores técnica e taticamente podiam "treinar" nas aulas de Educação Física. Esse movimento virou a base do atributo ideológico utilizado pela ditadura militar a desviar a atenção da população dos problemas de liberdade e políticos em que viviam. No fim dos anos 80 e inicio dos anos 90, a Educação Física começa a ganhar um novo formato, chamado de progressista. Dois trabalhos foram muito importantes para pensar uma nova forma de ensinar o esporte na escola, o Coletivo de Autores (1992) e a Transformação didático pedagógica do esporte (1994), com ênfase na aprendizagem do esporte, sem nenhum tipo de exclusão ou preconceito com os alunos.

\section{A IMPORTANCIA DE CONTINUAR O DEBATE}

A sociedade do espetáculo que preza pela vida não vivida, mas direcionada ao consumo, impossibilita o homem de se apropriar da produção material e de conhecimento mais desenvolvida até o momento. Os trabalhadores têm como atrativo para os detentores do meio de produção a venda de sua forma de trabalho, para que consiga minimamente sobreviver em uma sociedade direcionada ao consumo.

As manifestações da cultura corporal transformadas em esporte, produzem a exclusão social da maioria das pessoas, e garantem o fortalecimento do capital por meio da transformação de um simples jogo de futebol em espetacularização. É necessário questionar, discutir e debater as relações sociais e esportivas hegemônicas em nossa sociedade, para que esse sistema que vigora seja destruído, possibilitando o acesso de todos a toda produção humana.

A Educação Física crítica, tem como obrigação fortalecer o debate acerca do esporte, principalmente do esporte de alto rendimento, no contexto escolar, em eventos científicos e com a comunidade em geral.

Tirar do esporte os traços capitalistas de espetacularização é buscar uma nova forma de tratar as manifestações da cultura corporal na sociedade, de forma que todos possam ter acesso teórico/prático e que sua finalidade não seja o lucro de quem o patrocina.

\section{REFERÊNCIAS}

BRASIL. Lei Federal n. 8069, de 13 de julho de 1990. ECA _ Estatuto da Criança e do Adolescente. 
Universidade do Extremo Sul Catarinense

Revista Ibero-Americana de Humanidades, Ciências e

Educação

Unesc Produção e democratização do conhecimento na lbero-Améríca

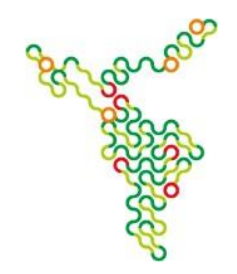

COLETIVO DE AUTORES. Metodologia do Ensino da Educação Física. São Paulo: Cortez, 1992.

COLOMBO, B. O esporte como estratégia de expansão do capital: as críticas, as contradições e as implicações para a Educação Física. XX Conbrace, Vitória, p. 1-13, 2015.

DEBORD, G. (1997). A Sociedade do Espetáculo. Rio de Janeiro: Contraponto.

JAPPE, A. Guy Debord. Trad. I. Poleti. Petrópolis: Vozes, 1999.

KUNZ, E. Transformação didático-pedagógica do esporte. ed. Ijuí: Ed. UNIJUÍ, 1994.

NASCIMENTO, C. P. Atividade pedagógica da Educação Física: A proposição dos objetos de ensino e o desenvolvimento das atividades da cultura corporal. São Paulo: s.n., 2014.

PIRES, G. L; SILVA, M. R. Os “negócios olímpicos” de 2016 no Brasil: “O esporte pode tudo?”. Motrivivência, Florianópolis, ano XXI, n. 32/33, junho-dezembro, 2009.

SILVA, A. M. Esporte espetáculo: a mercadorização do movimento corporal humano. Dissertação (Mestrado em Educação). Universidade Federal de Santa Catarina (UFSC). Florianópolis. 1999. 